On the other hand, many anthropologists, disregarding the rules of nomenclature, relegate all forms of Homo that do not differ structurally from what they loosely term 'modern man' to the sole species Homo sapiens, irrespective of geological age, geographical distribution or differences of a specific order.

The problem of the conspecificity of all living humanity has always been a thorny one. Allowing, however, for modern concepts of the status and limits of 'species', there is no reason to assume, as was once done, that acceptance of several species of living Homo necessarily implies a polygenic origin. If we are to be consistent and adhere to the general principles enunciated above, it is impossible to escape the view that there are several 'species' of living man, and several more fossil kinds. Moreover, some, if not all, these species have evolved geographical variants requiring trinomial nomenclature.

Many changes will be required if the above argument is to be acted upon, and new definitions will have to be prepared in certain cases. There will, no doubt, be plenty of scope for differences of opinion, but in any event the adoption of this or some similar scheme will assist in smoothing out considerable confusion. Space forbids the discussion of any details here, but one point that particularly comes to mind is the necessity of restricting the term Homo sapiens either to 'white man'-in which case Mediterranean, Alpine, etc., will become subspecies of it-or to some particular group of Europeans.

\section{Medical College,} Colombo.

${ }^{1}$ Le Gros Clark, W. E., Natrure, 145, 70 (1940).

' Sergi, G., L' Uomo (1908).

? Pycraft, W. P., Man (1925).

\section{Scope and Limitations of Physical Anthropology}

RECENT statements regarding physical anthropology are full of interest, but they omit the practical issue, which is the definition of a standard. During 1917-18, I was a medical officer employed in Egypt to assess the physical and mental capacity of soldiers, and decide who should be put into front line service and who should be employed in supporting services and in what capacity.

The story of national efficiency soon revealed itself. It is set out in a work of mine called "A Vision of the Possible". Some soldiers saw sufficiently well with glasses, some had some defective hearing on one side, and some had a varicose vein. I did not regard the vast majority of these as physically deficient, and, with the exception of those who had some ear disease, I could not see how anything could have been done to prevent these conditions. A vast number had bad teeth and were relegated at once to a large number of dentists stationed close to the front line, and were duly attended to.

In this respect I think something could be done in the way of national prevention. I believe I am correct in stating that the predynastic Egyptians, the original Hawaiian and Maories and the uncivilized (if it is justifiable to use such a term) Australian aborigines all had good teeth. The recent publication of the elaborate uncultivated diet of the Australian aborigine explains why he lived and thrived where civilized man died of starvation. But the Pharaohs suffered from dental disease, and so do the other races named, since contact with Europeans and different foods.

In the course of my work I realized that if the defects mentioned were regarded as barriers, there would be a sadly depleted army, and I am grateful that the commander-in-chief, Lord Allenby, endorsed this view and our action.

In the course of an investigation made long since, Lang and I found that in most wild animals refractive errors were not common, though certainly met with in some of the marsupials which have almost rudimentary eyes. But gross errors of myopia, hypermetropia and astigmatism were met with in many domesticated animals.

It is more than evident that Le Gros Clark, Mellanby and others have a powerful case for inquiry on the broadest basis possible, for the problem is not simple. But I conclude by stating that if you reject one man for refractive error, another for defect in one ear and so on, you get an utterly false standard of physical efficiency, and for that reason the usual figures given for rejection from the army never make any serious impression on me, as I think they do not express the common sense of the problem.

103-105 Collins Street, JAMES W. BARRETT.

Melbourne, C.1.

Jan. 3.

\section{Blood Groups of the Angami Nagas}

ReFerence has been made in NATURE ${ }^{2}$ to the report of the British Association Research Committee on Blood Groups among Primitive Peoples. The blood group percentages of the Angami Nagas, based on 96 tests, are given as follows:

$$
\begin{array}{cccc}
O & A & B & A B \\
35 \cdot 4 & 34 \cdot 4 & 25 \cdot 0 & 5 \cdot 2
\end{array}
$$

These differ greatly from those on the same people published by Capt. Mitra ${ }^{2}$, which are as follow :

$$
\begin{array}{cccc}
O & A & B & A B \\
46 \cdot 06 & 38 \cdot 78 & 11 \cdot 52 & 3 \cdot 64
\end{array}
$$

The percentage of $B$ given in the British Association data is thus more than double that published by Capt. Mitra and there is also an appreciable difference in blood group $O$. It is also stated in the British Association report that the blood group results accord with the view of Mr. J. P. Mills that the Konyaks are more primitive than the Angami-Rengmas, but if Capt. Mitra's Angami Naga results are compared with those of the British Association on the Konyaks, they appear to be closely similar. They are as follows:

$\begin{array}{llcccc} & \text { No. } & O & A & B & A B \\ \text { Angami (Mitra) } & 165 & 46 \cdot 06 & 38 \cdot 78 & 11 \cdot 52 & 3 \cdot 64 \\ \text { Konyak (B.A.) } & 127 & 45 \cdot 7 & 40 \cdot 2 & 10 \cdot 2 & 3 \cdot 9\end{array}$

The British Association results, however, confirm the predominance of $A$ over $B$ in this region excepting among the Thado-Kukis, which I also had pointed out in my recent paper on "Blood Grouping Investigations in India, with special reference to Santal Perganas, Bihar"s.

Bose Research Institute,

\section{S. S. SARKAR.} Calcutta.

Dec. 14.

2 NATURE, 144, 714 (1939).

"Mitra, P., N., "Blood Groups of the Angami Naga and Lushei Tribes", Indian J. Med. Re8., 23.(1935-36).

${ }^{3}$ Trans. Bose Research Institute, Calcutta, 12 (1936-37). 